\title{
Erratum to: Behavioral economics of food reinforcement and the effects of prefeeding, extinction, and eticlopride in dopamine $D_{2}$ receptor mutant mice
}

\author{
Paul L. Soto ${ }^{1}$ - David K. Grandy ${ }^{2}$ • Steven R. Hursh ${ }^{3}$ - Jonathan L. Katz ${ }^{4}$
}

Published online: 28 March 2015

(C) Springer-Verlag Berlin Heidelberg 2015

Erratum to: Psychopharmacology 215(4): 775 - 784.

DOI 10.1007/s00213-011-2173-z

Subsequent to publication, the authors discovered the following two errors: On page 778 (in the "Results" section), in the sentence at bottom right, beginning with "Follow-up ANOVAs...," the word "greater" in the phrase "values for the parameter obtained for the WT fits were significantly greater than," should be replaced with "less." Similarly, on page 779 (also in the "Results" section), in the first complete sentence, beginning with "Follow-up ANOVAs...," the word "greater" in the phrase "was significantly greater than," should be replaced with "less."

The online version of the original article can be found at http://dx.doi.org/ 10.1007/s00213-011-2173-z.

Paul L. Soto

psoto@jhmi.edu

1 Department of Psychiatry and Behavioral Sciences, Division of

Behavioral Biology, Johns Hopkins University, Ross 469, 720

Rutland Ave, Baltimore, MD 21205, USA

2 Oregon Health Sciences University, Portland, OR, USA

3 Department of Psychiatry and Behavioral Sciences, Division of

Behavioral Biology, Johns Hopkins University,

Baltimore, MD 21205, USA

4 National Institute on Drug Abuse, Baltimore, MD, USA 